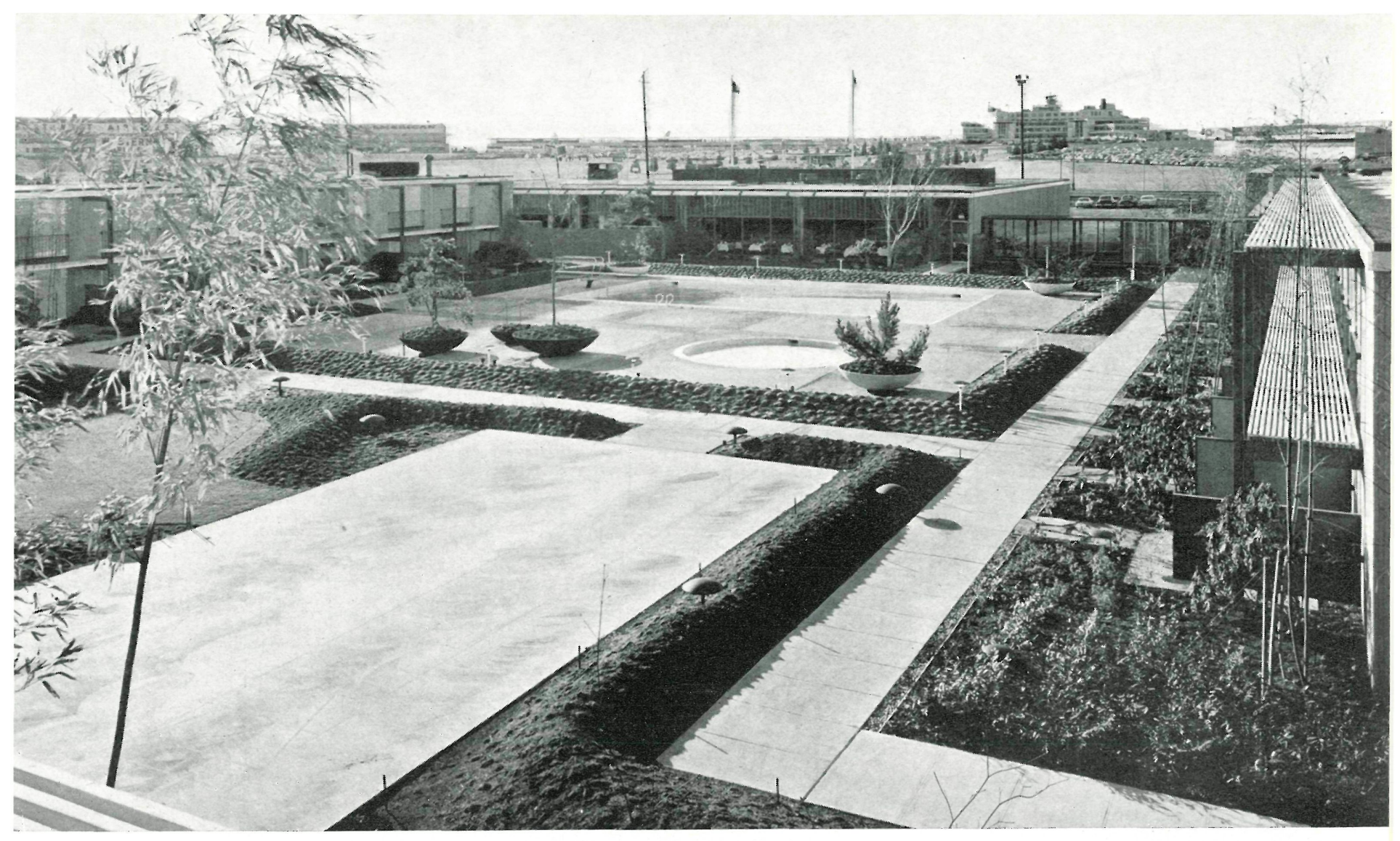

\title{
mote Hidi
}

\section{I.S.A.}

SKIDMORE, OWINGS

\& MERRILL,

arquitectos - ingenieros

$147-23$

\section{simopsis}

Consta este conjunto hotelero de: 4 edificios, de dos plantas de altura cada
uno, con un total de 150 habitaciones uno, con un total de 150 habitaciones para huéspedes; y de una edificación central, que contiene las zonas de:
recepción, conserjería, oficinas de la recepción, conserjería, oficinas de la administración, 2 restaurantes, cafete-
ría, salón de belleza, peluquería, etc.

Tanto la composición estética del exterior como la del interior, imprimen una gran sensación de intimidad a usuarios y visitantes. La organización en planta ha sido estudiada con sumo cuidado, a fin de obtener un funcionamiento perfecto del conjunto.
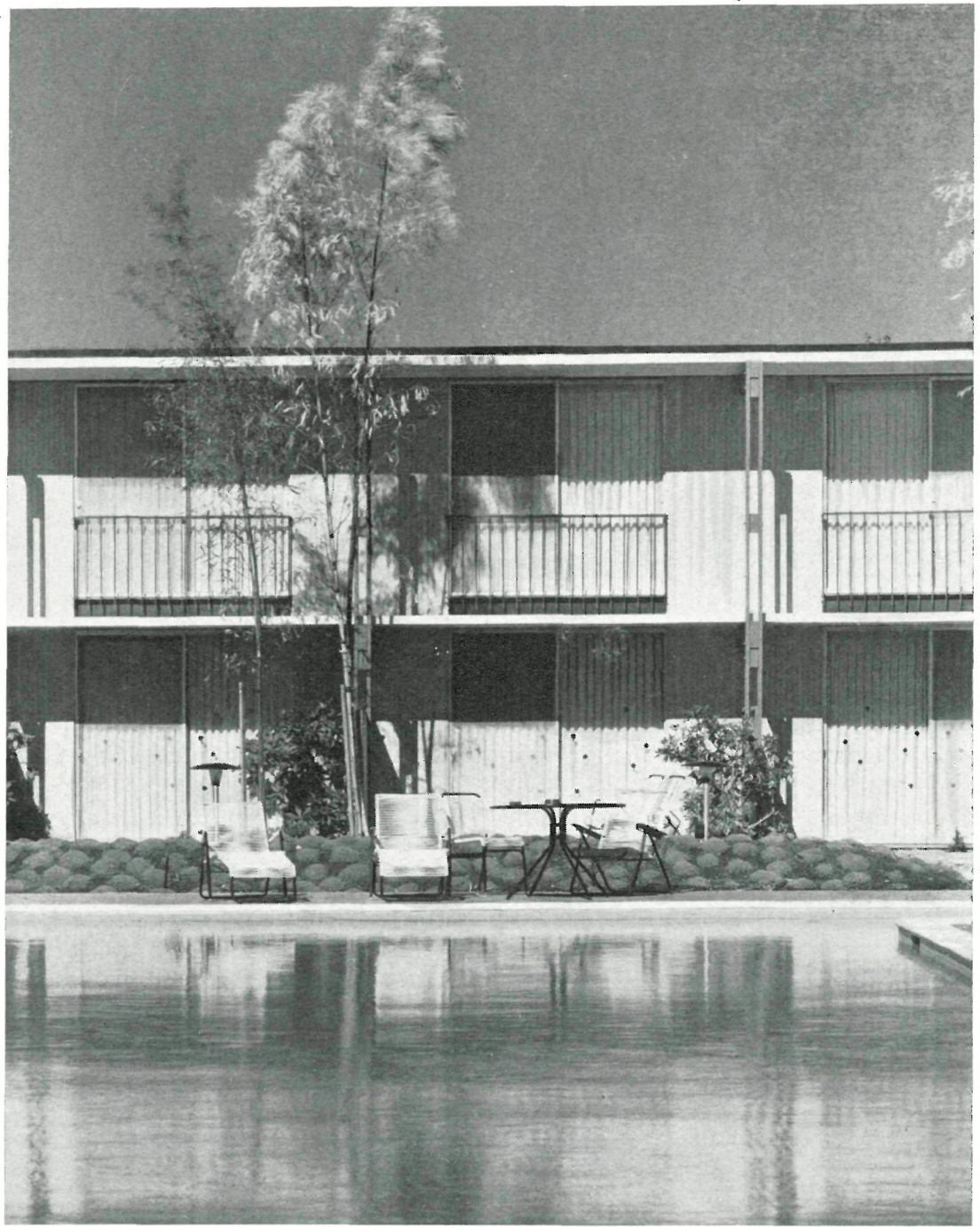
Al este del aeropuerto internacional de Seattle-Tacoma, en la carretera 99 U. S., sobre un terreno de $42.490 \mathrm{~m}^{2}$ de superficie y $194 \mathrm{~m}$ de fachada a la mencionada autopista ha sido erigido el Motel Hilton.

Consta de cuatro edificios, de dos plantas de altura cada uno, que albergan las habitaciones de los huéspedes, y de una edificación central, con $1.394 \mathrm{~m}^{2}$, además del sótano, el cual aloja: un restaurante con capacidad para 96 huéspedes; bar; otro restaurante para 80 personas, y una cafetería con asientos para 40 clientes. Una cocina central da servicio a los restaurantes.

El edificio aloja, asimismo, la zona de: recepción; conserjería; oficinas de la administración; vestíbulo; dos salones para múltiples usos, tales como celeración de congresos, asambleas, banquetes, etcetera, que pueden se ransformados en caso necesario en un espacio único, con asientos aproximadamente para 100 personas; salón de belleza; peluquería; etc

Los cuatro edificios ocupados por las habitaciones de los huéspedes comprenden un total de 150 dormitorios, todos ellos con baño, conectados por una serie de pasos cubiertos que circundan el conjunto.

Dichas habitaciones ocupan una superficie de $4.904 \mathrm{~m}^{2}$ y fueron proyectadas de forma que todas ellas recayeran a espacios exteriores tratados con un fino sentido paisajístico; 93 de las 150 habitaciones de huéspedes tienen vistas sobre el patio central, creado al tio central, creado al efecto, pavimentado y tratado con losas, árboles, césped y flores multicolores; además, se ha dispuesto una serie de zonas para actividades deportivas, piscina reglamentaria, pis-

En las habitaciones, algunas de las cuales pueden comunicarse para formar "suites", podemos distinguir tres tipos: 30 unidades de $4,42 \times 6,70 \mathrm{~m}$; 60 unidades de $3,96 \times 6,70 \mathrm{~m}$; y 50 unidades de $3,96 \times$ $\times 4,88$ metros.

Los elementos divisorios y los suelos han sido aislados acústicamente.

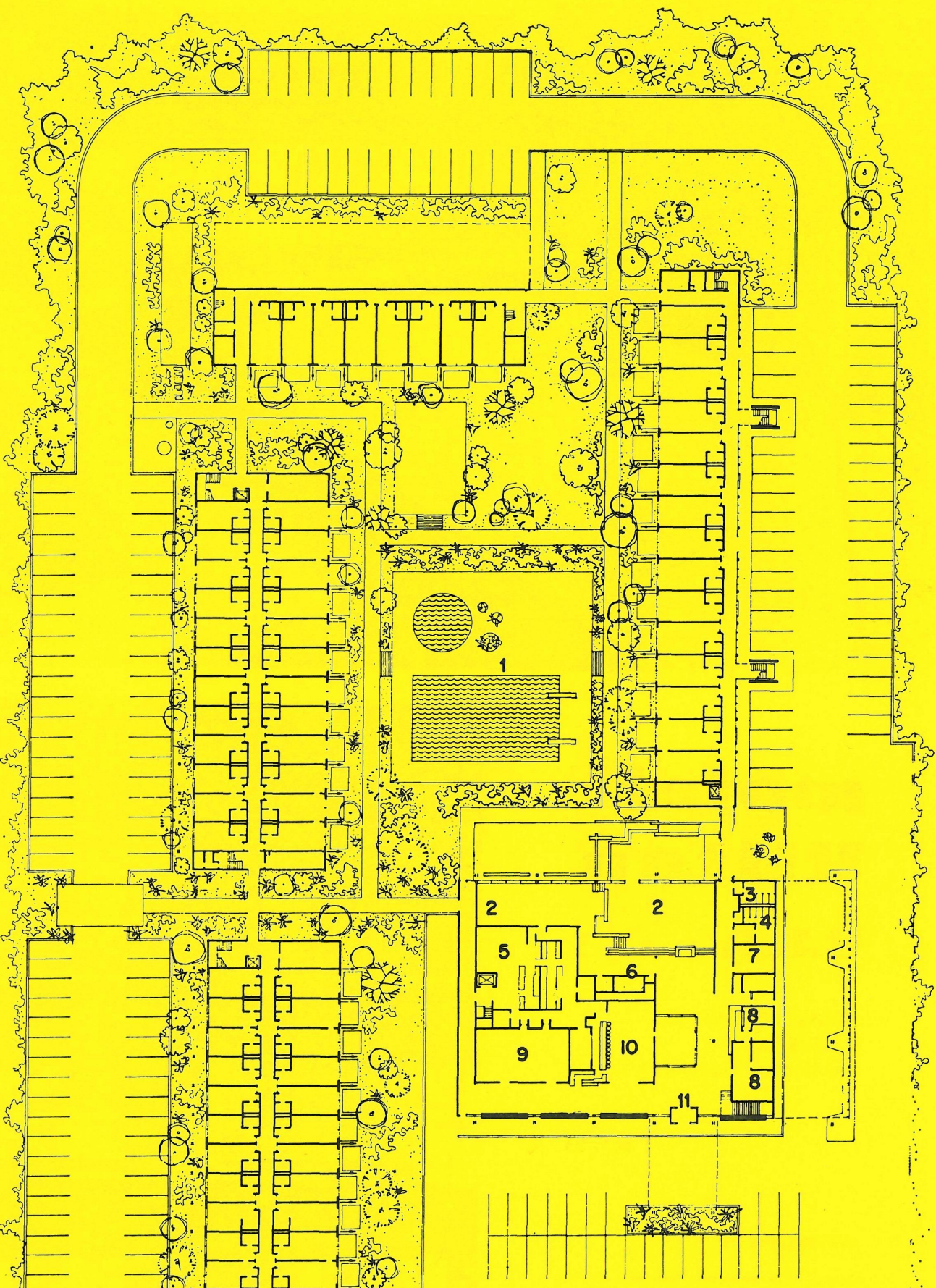

12

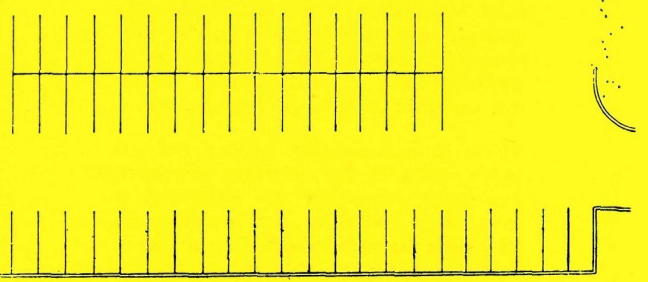

1017 1 1. Piscina.-2. Comedor.-3. Caballeros.-4. Señoras.-5. Cocina.-6. Guardarropa. 


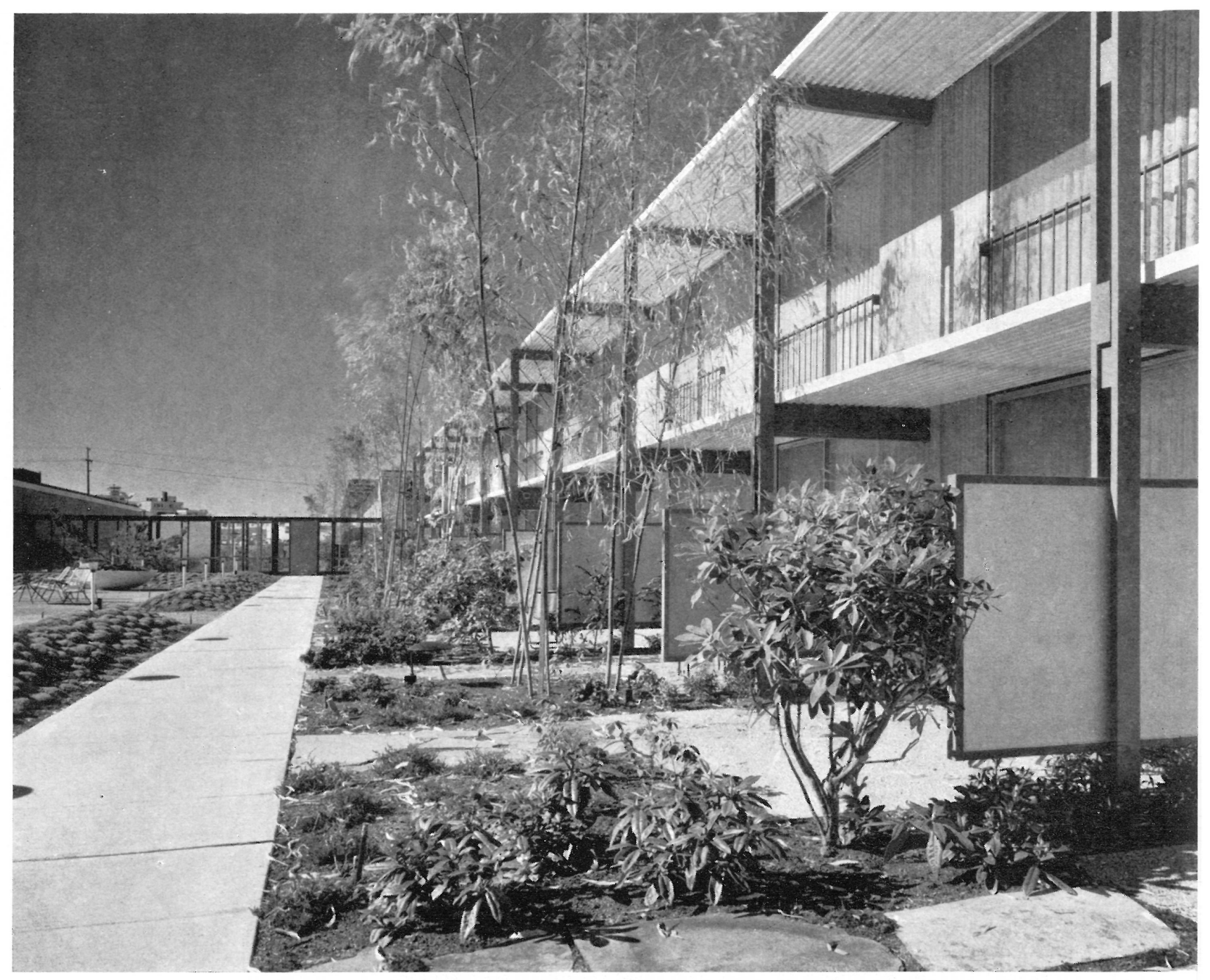

En la composición de las fachadas exteriores han sido combinados, con acierto y originalidad, la madera, la piedra y el cristal. Y los empanelados de madera, tanto en el interior como en el exterior, han ayudado a crear una atmósfera ambiental de calor y de quietud, que imprime una sensación acogedora al visitante.

Las áreas de aparcamiento fueron proyectadas con capacidad para 225 coches; distribuyéndose en varias zonas y de forma tal que, respetando las áreas de jardín, proporcionen un acceso fácil de los huéspedes usuarios a las habitaciones $\cdot y$ al edificio central.

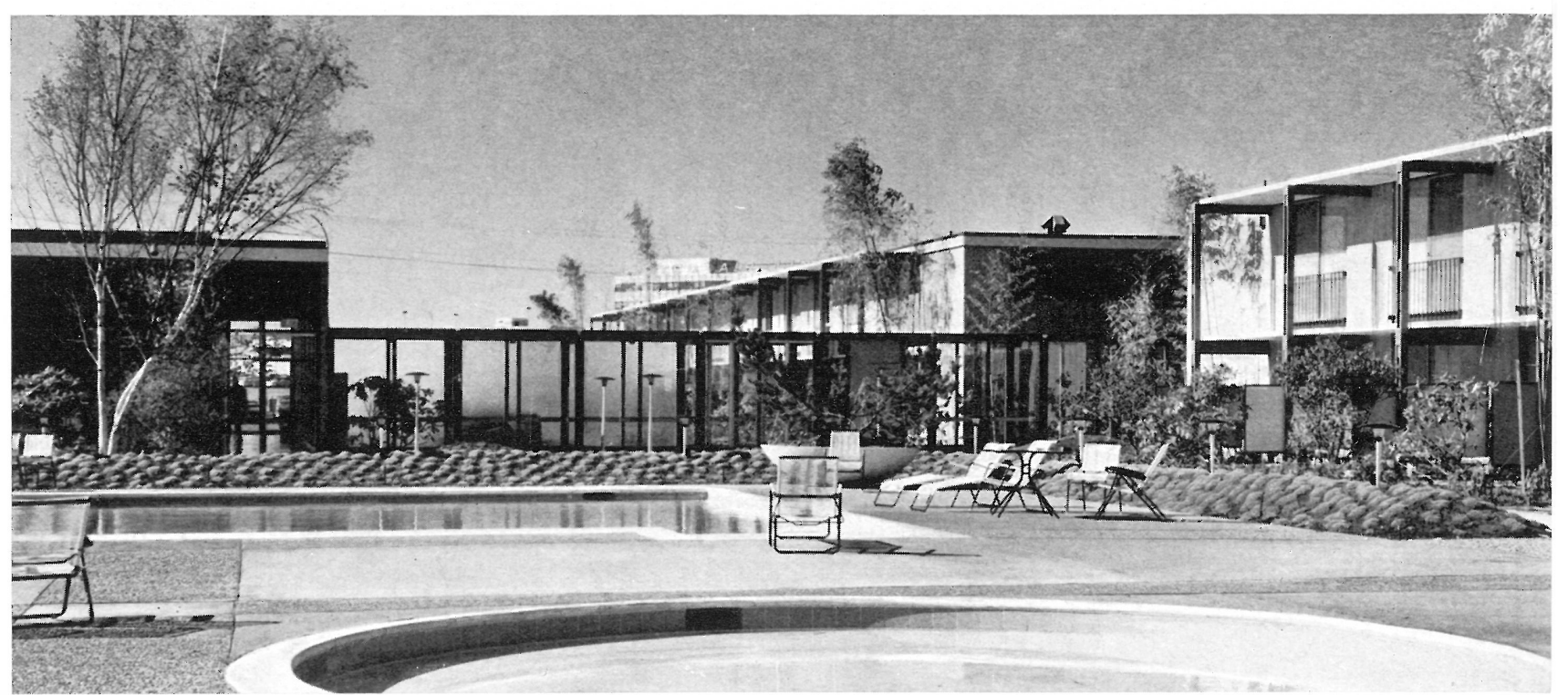




\section{Hôtel Hilton [U.S.A.]}

Skidmore, Owings \& Merrill, architectes-ingénieurs

Cet ensemble hôtelier se compose de quatre édifices, à deux étages chacun, comportant un total de 150 chambres, et d'un édifice central où se trouvent la réception, la conciergerie, les bureaux d'administration, deux restaurants, la cafeteria, le salon de beauté, le salon de coiffure, etc.

Autant la composition esthétique de l'extérieur que de l'intérieur donnent une grande sensation d'intimité aux usagers et visiteurs. L'organisation en plan a été très soigneusement étudiée, afin d'assurer un fonctionnement parfait de l'ensemble.

\section{Hilton Motel [U.S.A.]}

Skidmore, Owings \& Merrill, architects-engineers

This hotel system includes four buildings, each two storeys high, with a total of $\mathbf{1 5 0}$ guest rooms, and a central nucleus, where the reception rooms, offices, dorman's house, 2 restaurants, a cafeteria, a beauty saloon, hairdresser's shop and other facilities are located.

Both the external and internal architectural pattern and style aim at providing a highly intimate atmosphere to visitors. The distribution has been most carefully thought out, to ensure maximum fuctional efficiency.

\section{Hilton Hotel [U.S.A.]}

Skidmore, Owings \& Merrill, Architekte-Ingenieure

Dieser Hotelkomplex besteht aus: 4 Gebäude, je aus zwei Stockwerken; 150 Zimmer verteilt auf den 4 Gebäude; und aus einem Hauptgebäude, das enthält: Empfangshalle, Portierloge, Verwaltungsraum, zwei Restaurante, Cafeteria, Schönheitssalon,, Friseur, usw.

Die grösste Anziehung dieses Hotels besteht in den Gefühl von Innigkeit und der Eleganz und Einfachheit sowohl in der architektonischen Konzeption als auch in der Innendekoration. Der Betrieb von diesem Komplex ist perfekt. 